\title{
Research on the Development Model and Risk Identification in Tourism Urbanization
}

\author{
Chaochao Liang \\ School of Business Administration \\ Guizhou University of Finance and Economics \\ Guiyang, China
}

\begin{abstract}
Tourism urbanization has been widely applied and developed worldwide. It also has attracted the attention of many scholars. However, research on its potential risks still needs to be enriched. This paper combs previous literature and practical research to identify the risks in tourism urbanization. It is proposed that there are three development models of tourism urbanization, including tourism resources driven model, tourism market driven model and integrated elements driven model. Based on the research on the development model of tourism urbanization, it is concluded that the risks in tourism urbanization can be divided into ecological risks, social risks and economic risks. Finally, corresponding policy-level recommendations are put forward.
\end{abstract}

Keywords-tourism urbanization; tourism industry; development model; risk identification

\section{INTRODUCTION}

In comparison with urbanization driven by the industrialization, tourism urbanization is environment-friendly and has low economic cost, so it is advocated and supported around the world. It also has attracted the attention of many experts. The concept of tourism urbanization was firstly proposed by professor Mullins in Australia. From the perspective of tourism consumers, he defined tourism urbanization as the urban morphology based on the view of post-modernism consumption and city, which appeared in western developed countries in the late 20th century ${ }^{[1]}$. And according to professor Mullins, tourism urbanization was the model of urbanization based on hedonic selling and consuming [1]. Moreover, many other scholars have defined tourism urbanization from different perspectives including the specific features of urbanization connotation ${ }^{[2-4]}$, the driving force of urbanization ${ }^{[2-4]}$ and the facilitation of tourism industry to the city ${ }^{[2-4]}$. In extant research, the definition of tourism urbanization includes two major parts including the emphasis on the driven force of tourism industry and regional transformation in society, economy and natural environment in the tourism urbanization. Tourism urbanization is beneficial to protecting farmland, reducing environmental pollution, and preventing rural hollowing ${ }^{[5]}$. However, it is found that different risks exist in the process of tourism urbanization ${ }^{[6-8]}$. Through combing the relevant previous study, it is concluded that studies on the risks of tourism urbanization are dispersed and needed to be organized in the more systematic way. To

This work is supported by Project of 2019 Scientific Research for Students of Guizhou University of Finance and Economics (No. 2019ZXSY14). achieve that, the paper summarizes the development model of tourism urbanization which further provides support for the risks of tourism urbanization proposed. And the study enriches the research on the risks of tourism urbanization and is beneficial to promoting the practice of tourism urbanization in the reality.

\section{DEVELOPMENT MODEL OF TOURISM URBANIZATION}

For the different geographical position and natural environment of regions, local tourism industry is rich in diversity of influencing factors, presenting various of development path. Therefore, tourism urbanization, which is driven by the development of regional tourism industry, reports different development models. Combining the analysis on previous research and the study on the practice in reality, the paper divided the development model of tourism urbanization into three major types including tourism resources driven model, tourism market driven model and integrated elements driven model from the perspective of the driving force of tourism industry.

\section{A. Tourism Resources Driven Model}

Tourism resources driven model is the development model of tourism urbanization in which the urbanization is promoted by the development of regional tourism industry which is boosted through developing the rich tourism resources in the region. Tourism resources incorporate nature-based tourism resources, heritage and cultural tourism resources, and social tourism resources [9]. Developing nature-based tourism resources has made many regions increase their level of urbanization. The urbanization of many cities in Spanish and Australia has been promoted through developing the local beaches and ocean insights. Cities around Huangshan mountain, China have formed their own development model of tourism urbanization through developing the tourism resources of Huangshan mountain ${ }^{[10]}$. Moreover, cultural tourism is the important part of tourism industry. A variety of regions have improved their level of urbanization through developing heritage and cultural tourism resources and social tourism resources. The special culture of Stratford, a town in Canada, and Porto and Seguro, two towns in Brazil, has played important role in promoting the local urbanization ${ }^{[11]}$. Some ancient towns in China such as Zhouzhuang ancient town, Tongli town and Wuzhen town have attracted increasing 
people to build towns and formed their own development model of tourism urbanization. Most of regions developing through tourism resources driven model have enormous tourism resources, so can develop tourism landscapes to attract tourists and create working opportunities, attracting people nearby to the tourism landscape. In those regions, local people are mainly engaged in the secondary and tertiary industry.

\section{B. Tourism Market Driven Model}

It refers to the development model of tourism urbanization in which local tourism industry is driven by the tourism market which is next to the region and the development of local tourism industry facilitates the urbanization. Regions adopted the way of urbanization always hardly have various tourism resources but are in the neighborhood of big cities or large tourism landscape. The two important forms of tourism market driven model include developing rural tourism and build largescale amusement park or casino. The development of rural tourism requires that the environment in the rural country should be improved and that tourism industry and primary industry develop in coordination. And it has formed various development models including the tourism driven model of "tourist reception + country vacation+ leisure space" in French farm ${ }^{[13]}$, the tourism development model of B\&B of villages in Japan and South Korea ${ }^{[14]}$, agritainment and the new tourism model of the synthesis of sightseeing, leisure and vacation in Chinese villages ${ }^{[15]}$. Those models of rural tourism have improved the local living standard and the development of regional urbanization. Moreover, building large-scale amusement park or casino can attract tourists from cities and provide job opportunities for local people, promoting the sustainable prosperity in the region. The prosperity of Las Vegas in America is the typical example for tourism market driven model. And the building of HUIS TEN BOSCH, the biggest theme park for leisure and vocation in the Asia, also has facilitated the local urbanization.

\section{Integrated Elements Driven Model}

In that model, the development of the urbanization is driven by tourism resources and tourism market. There are two extreme situations. The first case is that the region is of enormous tourism resources and located next to large tourism market, so it has the natural advantage to promote the tourism urbanization like Hengshan County next to Mount Heng. The second case is that the region has some tourism resources, but its reputation is not big enough or covered by large scenic spots, and it is not close to the tourism market, so it only can be the potential destination on the traveling roundtrip route, like Xidi and Hongcun village in China.

\section{MAJOR RISKS OF TOURISM URBANIZATION}

Tourism urbanization can promote the prosperity of region but also has some risks which may hinder the further development of the region. Therefore, it is necessary to clarify the risks of tourism urbanization to facilitate the healthy and sustainable development of tourism urbanization. The risks of tourism urbanization refer to the possibilities of misfortune and the possible damages caused by the misfortune in the process of tourism urbanization. On the basis of the summarization of the development model of tourism urbanization, the paper posits that the risks of tourism urbanization include the ecological risks, social risks and economic risks.

\section{A. Ecological Risks}

Ecological risks refer that the possible negative effects on natural environment caused by the pushing of tourism urbanization. The development of tourism urbanization emphasizes the protection of original ecology and environment, energy conservation and emissions reduction since the development of tourism industry requires good natural environment. However, many cases report the negative effects caused by the development of tourism industry in the reality. David Sánchez-Quiles et al. found that components of sunscreens have negative effects on the coastal environment ${ }^{[6]}$. Krystyna Ciarkowska conducted research on the impact of tourist activities especially skiing activities on chemical and biochemical characteristics of soil of Zakopane, a tourism city. He found that the soil in tourist area was harmed much more seriously and the soil degradation here was very serious [7] Firstly, the development of tourism industry drives the population growth and generates much more pollution, increasing the environmental pressure on the region. Therefore, the region may face ecological risks. Secondly, parts of regions conducting tourism urbanization are in the mountain area or are close to oceans or lakes, so are venerable to suffer from natural disasters. In the process of tourism urbanization, natural and human landscape will be redeveloped. Unreasonable development of tourism resources will reduce the immunity of the natural environment, making it more vulnerable to natural disasters and facing ecological risks. Chung-Hung Tsai and Cheng-Wu Chen found that tourist attractions in Taiwan, China are always next to the mountain or ocean, so are vulnerable to be affected by natural disasters, making people engaging in tourism industry at great risk of natural disasters [16]. Thirdly, although the construction of large-scale amusement and gambling projects can improve the urbanization, it is easy to produce pollution and damage the regional environment, making cities and towns face ecological risks and hindering the sustainable development of urbanization. Fourthly, the development of tourism industry in small towns and villages often lacks comprehensive planning and cannot guarantee the environmental protection in the whole development process. Besides, people in those regions always have poor environmental awareness, so they are more likely to conduct behaviors damaging the environment in the development of tourism industry. Fragile natural and cultural environment and low quality of human capital increase the ecological risks in the tourism urbanization.

\section{B. Social Risks}

Social Risks refer that the development of tourism urbanization may accompany with some social problems, such as the loss of the traditional culture in the town, land problems and difficulties in the social administration. Firstly, the traditional culture in the town is easily to be harmed since it is intangible and just presents on carriers. Its carriers include not only constructions like museums and memorials, but also local residents. With the development of tourism urbanization, modern facilities, buildings and lifestyles will enter into the 
developing town. The collision of modern civilization and traditional culture may change the traditional culture in the town. The development of ancient towns such as Zhouzhuang town, Lijiang town and Fenghuang town reports that the entrance of modern civilization will significantly change the traditional customs and culture of those ancient towns. Secondly, land problems may be caused in the process of tourism urbanization. With the development of tourism urbanization, the leading role of tourism industry in the regional economy will become increasingly obvious, causing productive factors such as land of the primary and secondary industries gradually flow into the tertiary industry. In the process of land transfer, social contradictions may be generated and the town faces social risks. In addition, the overdevelopment of tourism industry may lead to the hollowing out of the primary and secondary industry. Thirdly, regional population mobility caused by tourism urbanization may exert pressure on the administration of society. The influx of tourists and labor force to the developing town may negatively affect the social administration of towns and make the town face the risk of social disorder. Tourism towns are often just temporary places for workers and tourists to stay, which may also lead to the risk of hollowing out of urban population.

\section{Economic Risks}

Economic risks are very common in the process of tourism urbanization. The development of tourism resources and tourism market, which are two important driving forces of tourism urbanization, needs a variety of financial support. However, small and medium-sized towns and rural areas often are in short of fund for the development of tourism industry, which requires the local government or the developer to apply for a loan from banks. Therefore, in large tourism projects, local government or developers often face huge financial pressure. If the development of tourism projects is not as expected, the risk of capital chain rupture may occur. Secondly, natural disaster will not only lead to ecological risks, but also cause economic risks since it affects the normal productive activities of tourism practitioners.

\section{CONCLUSION}

\section{A. Research Conclusion}

Based on the review on previous literature and the study on the realistic practice of tourism urbanization, the paper concludes three major development models of tourism urbanization including tourism resources driven model, tourism market driven model and integrated elements driven model from the perspective of the driving force of the development of tourism industry. And it is further proposed that the ecological risks, social risks and economic risks exist in the process of tourism urbanization.

\section{B. Policy Proposal}

1) Forming a flexible and comprehensive development plan of tourism urbanization

Before determining the development model of tourism urbanization and formulating corresponding plans, local government should comprehensively consider factors including regional tourism resources and geographical location. When local government formulates the development plan of tourism urbanization, it should take the ecological risks, economic risks, social risks and various possible accidents into account. Local government also should maintain dynamic supervision on the development of tourism urbanization and make regular assessment of the ecological, social and economic risks of local tourism urbanization. Moreover, the selection of developers of important tourist attractions should be very cautious. Local government should choose those with high environmental awareness, rich capital reserves and comprehensive planning for the development of tourist attraction. In the cooperation with developers, the government should not only protect the interests of them, but also effectively restrain their behaviors.

\section{2) improving industrial policies}

Local government is not the developer but the supervisor and guider of the development of tourism industry. Therefore, local government should introduce a series of environmental protection policies and tourism industry policies, build supporting infrastructure, create a good environment for the development of tourism industry, and stimulate the enthusiasm of tourism practitioners. In addition, local government should introduce relevant policies to promote the integrated development of primary, secondary and tertiary industry and facilitate the development of regional economy through boosting the development of tourism industry.

\section{3) Improving the quality of regional human capital}

Human capital plays an important role in promoting the development of tourism urbanization. Local government should attach great importance on the improvement of the quality of regional human capital. It should require developers to train workers in scenic region on environmental protection thoughts and service concepts to strengthen workers' environmental protection awareness and service awareness and make them master the ability to put environmental protection and service concepts into action. Moreover, local government should implement flexible population management policies, formulate talents introduction policies, and vigorously attract talents in the tourism industry. In order to provide talents for the development of regional tourism industry and tourism urbanization, basic education in the region should be strengthen to improve the overall quality of resident. 


\section{REFERENCES}

[1] Mullins P. Tourism urbanization.[J]. International Journal of Urban \& Regional Research, 2010, 15(3):326-342.

[2] Sun Li. A review of the theoretical connotation and development of tourism urbanization. [J]. China Market,2013(04):73-75. (In Chinese)

[3] GAO Jing-ting, LI Guo-yin. A Study Review on China's Tourism Urbanization [J]. Economic Research Guide,2011(07):180-182. (In Chinese)

[4] LU Lin , GE Jing-bing. Reflection on the research progress of tourism urbanization. [J]. Geographical Research,2006(04):741-750. (In Chinese)

[5] BAO Jigang, MENG Kai1, ZHANG Qianying. Rural urbanization led by tourism-A Case Study of Li village in Yangsu County, China [J]. Geographical Research,2015,34(08):1422-1434. (In Chinese)

[6] Sánchezquiles D, Tovarsánchez A. Are sunscreens a new environmental risk associated with coastal tourism?[J]. Environment International, 2015, 83:158-170.

[7] Ciarkowska K. Assessment of heavy metal pollution risks and enzyme activity of meadow soils in urban area under tourism load: a case study from Zakopane (Poland).[J]. Environmental Science \& Pollution Research, 2018(8):1-10.

[8] CHENG Tianxu. Research on the negative effect of tourism urbanization of Huangshui town [J]. Journal of Chongqing University of Arts and Sciences (Social Sciences Edition) ,2017,36(01):114-118. (In Chinese)

[9] Du Youzhen, Pei Yuchang, Wu Hongliang. Introduction to tourism [M]. Southwest China Normal University Press,December 2007. (In Chinese)

[10] Li Peng. Research on the mode and regulation of tourism urbanization [J]. Social Scientist,2004(04):97-100. (In Chinese)

[11] Anne H J, Geoffrey W, Jason F. Creative food clusters and rural development through place branding: Culinary tourism initiatives in Stratford and Muskoka, Ontario, Canada[J]. Journal of Rural Studies, 2015, 39: 133-144

[12] ZHANG Dong-ting,QIU Fu-dong. A Summary of Ancient Town Tourism Studies at Home and Abroad [J]. Tourism Tribune,2011,26(03):86-92. (In Chinese)

[13] FANG Zhongquan, GUO Yixian. Rural tourism of France and its significance to us [J]. Journal of Guangzhou University (Social Science Edition), 2008, 7(3):32-36. (In Chinese)

[14] Parka D, Yoonb Y. Segmentation by motivation in rural tourism: A Korean case study[J]. Tourism Management, 2009, 30(1): 99-108

[15] Zhao Xiyong,Wu Hongyan,Wang Yongmei,Na Shouhai. The Rural Tourism to promote the new urbanization-Jilin province Jinzhou village as an example [J]. Chinese Journal of Agricultural Resources and Regional Planning,2017,38(06):164-169+177. (In Chinese)

[16] Tsai $\mathrm{C} \mathrm{H}$, Chen $\mathrm{C} \mathrm{W}$. The establishment of a rapid natural disaster risk assessment model for the tourism industry [J]. Tourism Management, 2011, 32(1):158-171. 